\title{
Correction to: Genetic susceptibility to neuroblastoma: current knowledge and future directions
}

\author{
Laura E. Ritenour ${ }^{1,2,3} \cdot$ Michael P. Randall ${ }^{2,3,4} \cdot$ Kristopher R. Bosse ${ }^{2,3,4} \cdot$ Sharon J. Diskin ${ }^{1,2,3,4,5}$ \\ Published online: 8 September 2020 \\ (C) Springer-Verlag GmbH Germany, part of Springer Nature 2020
}

Correction to: Cell and Tissue Research (2018) 372:287-307 https://doi.org/10.1007/s00441-018-2820-3

The online HTML version of the article contains an error in Table 2. In the second-to-last row of the table (beginning with "3p21.31"), the column "Reference/alternate allele" should list "T/A" instead of "A/G." This error was corrected in the print and online PDF versions before publication of the issue, but the online HTML version was inadvertently left uncorrected.

Publisher's note Springer Nature remains neutral with regard to jurisdictional claims in published maps and institutional affiliations.

The online version of the original article can be found at https://doi.org/ 10.1007/s00441-018-2820-3

Sharon J. Diskin

diskin@email.chop.edu

1 Cell and Molecular Biology Graduate Group, Perelman School of Medicine, University of Pennsylvania, Philadelphia, PA, USA

2 Division of Oncology, Children's Hospital of Philadelphia, Philadelphia, PA, USA

3 Center for Childhood Cancer Research, Children's Hospital of Philadelphia, Philadelphia, PA, USA

4 Department of Pediatrics, Perelman School of Medicine, University of Pennsylvania, Philadelphia, PA, USA

5 Abramson Family Cancer Research Institute, Perelman School of Medicine, University of Pennsylvania, Philadelphia, PA, USA 